\title{
Effects of an adapted physical activity program on the physical condition of elderly women: an analysis of efficiency
}

\author{
Efeitos de um programa de atividade física adaptada na capacidade física e \\ parâmetros de saúde de mulheres idosas: análise de eficiência
}

Francisco Alburquerque-Sendín', Enzo Barberio-Mariano², Naja Brandao-Santana², Daisy A. N. Rebelatto², José R. Rebelatto³

\begin{abstract}
Background: Specific research tools and designs can assist in identifying the efficiency of physical activity in elderly women. Objectives: To identify the effects of physical activity on the physical condition of older women. Method: A one-year-long physical activity program (123 sessions) was implemented for women aged 60 years or older. Four physical assessments were conducted, in which weight, height, $\mathrm{BMI}$, blood pressure, heart rate, absences, grip strength, flexibility, $\mathrm{VO}_{2 \max }$, and static and dynamic balance were assessed. The statistical analyses included a repeated measures analysis, both inferential (analysis of variance - ANOVA) and effect size (Cohen's $d$ coefficient), as well as identification of the participants' efficiency (Data Envelopment Analysis - DEA). Results: Despite the observation of differences that depended on the analysis used, the results were successful in the sense that they showed that physical activity adapted to older women can effectively change the decline in physical ability associated with aging, depending on the purpose of the study. The 60-65 yrs group was the most capable of converting physical activity into health benefits in both the short and long term. The $>65$ yrs group took less advantage of physical activity. Conclusions: Adherence to the program and actual time spent on each type of exercise are the factors that determine which population can benefit from physical activity programs. The DEA allows the assessment of the results related to time spent on physical activity in terms of health concerns. Article registered in Clinicaltrials.gov under number NCT01558401.
\end{abstract}

Key words: physical therapy; physical activity; elderly; women; efficiency.

\section{Resumo}

Contextualização: Ferramentas e desenhos específicos de pesquisa podem ajudar na identificação da eficiência da atividade física em mulheres idosas. Objetivos: Identificar os efeitos da atividade física sobre a eficiência da condição física de mulheres idosas. Método: Aplicou-se um programa de atividade física de um ano (123 sessões) para mulheres com idade de 60 anos ou mais. Foram realizadas quatro coletas de dados físicos, avaliando peso, altura, índice de massa corporal (IMC), pressão arterial, frequência cardíaca, ausências, força de preensão, flexibilidade, $\mathrm{VO}_{2 \max }$, além de equilíbrio estático e dinâmico. As análises estatísticas incluíram uma análise de medidas repetidas, tanto inferencial (análise da variância - ANOVA) quanto do tamanho do efeito (coeficiente $d$ de Cohen), além da identificação da eficiência dos participantes (análise por envoltório de dados - DEA). Resultados: Apesar das diferenças observadas nos resultados das análises realizadas, eles permitiram apontar que a atividade física adaptada para mulheres idosas pode efetivamente mudar as capacidades físicas associadas ao envelhecimento. As mulheres com idades entre 60-65 anos são mais capazes de reverter a atividade física em benefícios para a saúde no curto e longo prazo. No entanto, as mulheres mais velhas, dentro do grupo >65 anos, tiveram mais dificuldade em tirar proveito da atividade física. Conclusões: A adesão ao programa e o tempo gasto em cada tipo de exercício determinam a população que pode se beneficiar de programas de atividade física. A DEA permite ponderar os resultados relativos ao tempo de atividade física realizada em termos de condições de saúde. Registrado no Clinicaltrials.gov sob o número NCT01558401.

Palavras-chave: fisioterapia; atividade física; idoso; mulheres; eficiência.

Received: 02/03/2012 - Revised: 03/23/2012 - Accepted: 03/23/2012

'Department of Physical Therapy, University of Salamanca, Salamanca, Spain

2Department of Production Engineering, Escola de Engenharia de São Carlos, Universidade de São Paulo (USP), São Carlos, SP, Brazil

${ }^{3}$ Department of Physical Therapy, Universidade Federal de São Carlos (UFSCar), São Carlos, SP, Brazil

Correspondence to: Francisco Alburquerque Sendín, University of Salamanca, Department of Physical Therapy, C/Donante de Sangre, s/n, Postal Code: 37007 , Salamanca, Spain

e-mail: pacoalbu@usal.es 


\section{Introduction $: \therefore$.}

The world's population is aging. In 2003, Brazil's elderly population was 16.7 million: $9.6 \%$ of its total population. It is estimated that by 2020 the elderly will make up 13\% of Brazil's population ${ }^{1}$. Aging is characterized by morphological and physiological changes, such as loss of muscle strength, flexibility, and balance, and other deficits in physical function ${ }^{2,3}$, particularly in women ${ }^{4}$. In conjunction with these processes, there are variations in body composition and anthropometry (a reduction in weight, height, and bone mineral density) and these are exacerbated by the more sedentary lifestyle of older individuals ${ }^{5,6}$, which affects their quality of life $^{7}$ and increases the risk of falls, especially in women ${ }^{8}$. Furthermore, it has been identified that Brazilian women show variations in their fitness relative to other populations?

Although physical activity programs for the elderly have been shown to curb the harmful changes of aging ${ }^{10,11}$, not all programs have the same effectiveness ${ }^{12,13}$ despite being generally regarded as effective ${ }^{14}$. The existence of a wide variety of programs $s^{15}$ calls for debate about their outcomes ${ }^{13,16}$, which in turn implies carrying out studies on population subgroups using different types of analysis ${ }^{13,16-19}$.

Specific research tools and designs can assist in identifying not only program effectiveness but also program efficiency and use in terms of better physical performance, which is influenced by multiple factors including adherence to the program ${ }^{20}$. These analyses allow the assessment of the influence of efficiency and the factors that determine it or are associated with it and can provide classifications and subgroups to which interventions should be adapted if they are to offer the best service in the short and medium term ${ }^{19}$. Therefore, the purpose of this study was to identify the effects and efficiency of an adapted physical activity program as regards the physical condition of older Brazilian women.

\section{Method : :}

\section{Participants}

Participants were selected from among a group of 120 elderly women $\left(>60 \mathrm{yrs}^{21,22}\right.$ ) included in an Adult Revitalization Program in São Carlos, SP, Brazil. Initially, all participants underwent a medical evaluation of their physical characteristics and previous health problems that might hinder their participation in the program activities ${ }^{23}$. Participants were excluded if they did not come to one or more of the physical evaluations conducted at the beginning and throughout the program, and those whose adherence to the program sessions was lower than
$75 \%$ were also excluded. Thus, this study included 64 women with a mean age of $66.92 \pm 5.41$ years. This sample was analyzed as a group (>60 yrs group) and was divided into two subgroups by age: the $60-65 \mathrm{yr}$ subgroup ( $\mathrm{n}=31,62.45 \pm 1.82$ years) and the $>65$ yr subgroup ( $\mathrm{n}=33,71.12 \pm 4.11$ years).

All participants signed an informed consent form and declared that they were not participating in other specially designed physical activities outside the program. The study was conducted in accordance with resolution 196/96 of the National Health Council (CNS) and was approved by the Human Research Ethics Committee of Universidade Federal de São Carlos (UFSCar), São Carlos, SP, Brazil (Document No. 104/4). This study was registered at Clinicaltrials.gov (NCT01558401).

\section{Outcome measures}

Participants were evaluated individually according to different inputs (amount of time in days spent on strength, flexibility, and aerobic exercises) and outputs (levels of grip strength, flexibility, static balance, dynamic balance, and $\mathrm{VO}_{2 \max }{ }^{23}$ in four assessments (A1, A2, A3, and A4). Grip strength was measured using a Sammons Preston Swedley-Type hand dynamometer $\left(\text { Jamar }^{\circledR} \text {, Bolingbrook, IL, USA) }\right)^{24,25}$. The test was performed three times on the dominant upper limb at 10-second intervals between each run. The grip strength assigned to each participant was the highest of the three values measured. The participants were instructed to hold the grip meter during exhalation without performing the Valsalva maneuver; they were encouraged verbally throughout the test ${ }^{26}$. Reliability studies have shown that handgrip strength measured with the Jamar dynamometer is a reliable method (ICC $>0.85$ ) and is recommended for use in clinical practice ${ }^{27}$.

The Sit-and-Reach Test was employed to evaluate lower back and lower limb flexibility ${ }^{28}$. The movement was performed three times. The flexibility assigned to the participants was the highest value measured ${ }^{29}$. Previous studies have indicated that reliability estimates for the Sit-and-Reach Test are consistently high in elderly women (ICC $=0.98)^{30}$.

Static balance was verified by the One-Leg Stance Test with eyes open ${ }^{31}$. The participants gazed at a fixed point two meters away for no more than 30 seconds, with one leg bent at the knee. The test was performed three times with eyes open and closed and with both legs, taking into account the mean value of the measures for each condition (eyes open or closed). This procedure has high inter-rater reliability $(\text { ICC }=0.93)^{32}$.

Dynamic balance was evaluated by Maximum Gait Velocity $(\mathrm{MGV})^{33,34}$. The participants were instructed to walk along a $33.3 \mathrm{~cm}$-wide and $3.33 \mathrm{~m}$-long track painted on the floor in the shortest possible time. The test was performed three times. The dynamic balance value assigned to each participant was 
the mean time spent walking along the track. The coefficient of variation for healthy elderly women varies between 0.09 and $0.14^{35}$. The Rockport 1-Mile Walk Test was used to determine physical condition estimated by the $\mathrm{VO}_{2 \max }{ }^{36}$. The test-retest reliability coefficient of this test has been considered high (0.97) by different authors ${ }^{37,38}$.

The following variables were also determined by trained research staff, using standardized protocols at each assessment ${ }^{39}$ : height, weight, body mass index (BMI), heart rate, and systolic and diastolic pressures. Height was measured to the nearest centimeter using a portable stadiometer. The participants removed their shoes, stood with their back to the stadiometer maintaining erect posture and looking straight forward during height measurement. Weight was measured on a scale with the participants in undergarments. Both the stadiometer and the scale had been calibrated previously. Resting pulse rate and resting blood pressure were measured after a minimum 10minute rest period. Pulse rate was measured manually twice for one minute at the radial artery of the left wrist. Resting blood pressure was measured manually twice on the left arm with a hand aneroid sphygmomanometer and stethoscope. All physical measurements were collected twice, and the mean of the two values was used in analysis. Adherence to the program (absenteeism) was also assessed.

\section{Intervention}

The physical activity program consisted of 123 sessions carried out over a period of 52 weeks. The first assessment (A1) was performed, followed by 12 weeks of activities. Next, the second assessment (A2) was performed, followed by three weeks of rest and another 17 weeks of activities. Then the third assessment (A3) was conducted, followed by four weeks of activities, four weeks of rest, and finally 12 more weeks of activities. After that the fourth assessment (A4) was performed. The A1-A2 period comprised 30 sessions, the A2-A3 period 48 sessions, and the A3-A4 period 45 sessions. The rest periods coincided with the workers' vacation periods.

The sessions were held in groups of no more than 25 participants, and the activities were standardized and agreed upon by the research team, which held monthly meetings. Each session consisted of 8-10 minutes of stretching of the major muscle groups (pectoral, latissimus dorsi, cervical paravertebral, and posterior and anterior thigh muscles); 9 minutes of aerobic exercise (fast walking); 7-10 minutes of adapted strength, power, and endurance training (with load determined by the participants and increased as needed according to the supervisors); 14-16 minutes of coordination, agility, and flexibility exercises, and 5-7 minutes of respiratory and relaxation exercises. The sessions were performed three times a week.
Based on previous studies ${ }^{23}$, this activity protocol is in accordance with recommended time and intensity parameters ${ }^{40}$, allowing control and quantification of the activities performed overall and during each exercise. The sessions were supervised by previously trained physical educators and physical therapists. The research team ensured that the participants performed the activities as correctly as possible and that the exercises were varied in order to keep them motivated, as suggested in the literature ${ }^{41}$.

\section{Sample size}

Sample size was determined with the ENE 3.0 (GlaxoSmithKline, London, UK) software. The calculations were based on detecting an effect size of $6.4 \mathrm{~s}$ of the static balance, verified by the One-Leg Stance Test with eyes open (Preintervention: 18.5s; Postintervention: 25.9s), with a standard deviation of $7.7 \mathrm{~s}$ at postintervention data ${ }^{42}$, an $\alpha$ level of $5 \%$, and a desired power of $90 \%$. These assumptions generated a desired sample size of at least 31 subjects per group.

\section{Statistical analyses}

Statistical analyses were conducted with the SPSS 19.0 package (SPSS, Chicago, IL). The means and standard deviations or $95 \%$ Confidence Intervals $(95 \% \mathrm{CI})$ for each of the outcome measures are shown. The Kolmogorov-Smirnov test showed normal distribution of the quantitative data $(p>0.05)$. One-way repeated-measures ANOVA, with assessment (A1, A2, A3, A4) as the within-subject factor, was performed to examine the effects of the intervention on the physical ability of the group ( $>60 \mathrm{yrs}$ ) and subgroups (60-65 yrs and $>65 \mathrm{yrs}$ ). The Bonferroni test was used for post-hoc analysis between assessments A1-A2, A1-A3, and A1-A4. Within-subject comparisons (A1-A2, A1-A3, A1-A4) and comparisons between efficient and non-efficient individuals in the group and subgroup effect sizes were calculated using the Cohen index $(d)^{43}$. An effect size greater than 0.8 was considered large, 0.5 moderate, and less than 0.2 small.

The operational research tool, Data Envelopment Analysis (DEA), was used to determine the relative efficiency of the participants, considered Decision-Making Units (DMUs) ${ }^{44-46}$. This analysis supports the hypothesis that the outputs do not need to be proportional to the inputs ${ }^{47}$. In this case, the inputs were the amount of time in days of strength, flexibility, and aerobic exercises, and the outputs were the levels of strength, flexibility, static balance, dynamic balance, and $\mathrm{VO}_{2 \max }$, verified at the end of the physical activity program ${ }^{47,48}$. After that, an unrepeated Student-t test was employed to compare the results between efficient and non-efficient women for all variables 
not considered outputs (BMI included) for each group and assessment. The statistical analysis was conducted at a $95 \%$ confidence level. A $p$ value of less than 0.05 was considered statistically significant for all analyses.

\section{Results $: \because$.}

The descriptive results of the outcomes for the group and subgroups at the four assessments are shown in Table 1. The time spent on strength and aerobic endurance exercises was similar and, in all cases, longer than the time spent on stretching exercises. Nevertheless, the activity program was more effective in changing flexibility than any other physical ability, when minimum, if the participants were categorized by age, i.e., 60-65 yrs and >65 yrs (more than $20 \mathrm{~mm}$ in some cases). In fact, dynamic and static balance, especially of the left limb, was another parameter strongly influenced by physical activity (4.67 seconds for the > 65 yrs subgroup between A1 and A4) despite the fact that there were no exercises specifically aimed at recovering and preserving this ability.

\section{Repeated-measures analyses and the Cohen index of the group and subgroups}

All physical variables in conjunction with BMI showed statistically significant differences in the ANOVA test for the total sample (>60 yrs group), pointing to an increase between assessments $\mathrm{A} 1$ and $\mathrm{A} 3$ in terms of strength, flexibility, and $\mathrm{VO}_{2 \max }$ and a decrease in the last assessment (A4), breaking the trend even though the A3-A4 interval comprised more activity time on all types of exercise. When the subgroups were taken into account, the overall results showed a similar, albeit more heterogeneous, behavior. The more elderly subjects ( $>65 \mathrm{yrs}$ ) tended to generate more change in the ANOVA (flexibility, left limb static balance, and maximum gait velocity showed $p$-values lower than 0.001 ). These differences were maintained in the post-hoc analysis: flexibility (A1-A2, A1-A3, A1-A4), $\mathrm{VO}_{2 \max }$ (A1-A3), LLS test (A1-A2, A1- A3, A1-A4), and MGV (A1-A2, A1-A4) (Table 2).

The Cohen index did not show the same distribution of differences found in the inferential analysis, indicating low or moderate values. Only the $>65$ yrs subgroup achieved moderate values $(>0.5)$ with regard to balance, especially in the long term (A1-A4). BMI changed very little, with values lower than 0.1. Most of the variables showed size effects around 0.2 (small effect). In addition, some variables showed a negative effect in the A1-A2 period, $\mathrm{VO}_{2 \max }$ being the most representative, in conjunction with dynamic balance, which decreased moderately, as in the ANOVA (Table 3).

\section{Efficiency analysis (DEA) and Cohen index of efficiency}

The efficiency analysis showed two homogeneous types of behavior. First, considering the $>60$ yrs group, the A3 assessment afforded the smallest percentage of efficient women (Table 4), even though only the 60-65 yrs subgroup included a larger number of efficient women at the end of the program (A4) than in the short term (A2). Second, the 60-65 yrs subgroup attained the largest number of efficient women in all three assessments (A2, A3, A4), which indicates that this age range benefits the most from the activities carried out although the effect sizes were not the largest nor did they constantly reach significance.

Apart from this initial analysis, we identified the non-output variables that were different depending on individual efficiency or non-efficiency within the group and subgroups. This showed that age was the sole factor in the determination of differences $(\mathrm{p}<0.05)$ in the $>60$ yrs group (A3: efficient $=65 \pm 4.1$ years, nonefficient women $=68.62 \pm 5.89$ years; A4: efficient women $=$ $65 \pm 2.07$ years, non-efficient women $=69.39 \pm 2.4$ years $)$ and in the $>65$ yrs subgroup (A3: efficient women $=68.22 \pm 2.82$ years, non-efficient women $=71.55 \pm 4.93$ years; $\mathrm{A} 4$ : efficient women $=68.10 \pm 3.25$ years, non-efficient women $=72.21 \pm 4.56$ years) groups. The 60-65 yrs subgroup showed no dependence on the factors discussed and no differences between the efficient and non-efficient women ( $\mathrm{p}>0.05)$.

Finally, taking into account the group and subgroups, the behavior measured by the Cohen index of the efficient individuals was much higher than that of non-efficient individuals, especially in A2 and A4. In fact, variables such as static balance behaved very differently among individuals, with large effects, several of them above one. Moderate effects were identified for flexibility, oxygen consumption, and some BMI assessments. Both strength and dynamic balance showed small differences between the efficient and non-efficient women, albeit with exceptions (MGV-A4, >65 yrs subgroup; strength-A3/A4, 60-65 yrs subgroup). The 60-65 yrs subgroup exhibited differences between the efficient and non-efficient women from A2 onward, whereas older subjects ( $>65$ yrs) took longer to exhibit significant benefits from the program only after A3 (Table 5).

\section{Discussion $: \because$.}

The results of this study indicate that prolonged adapted physical activity generates changes of different magnitudes and interpretations in older women. Likewise, for the older group of older women, age seems to be a determining factor as regards program efficiency. Efficiency itself could be 


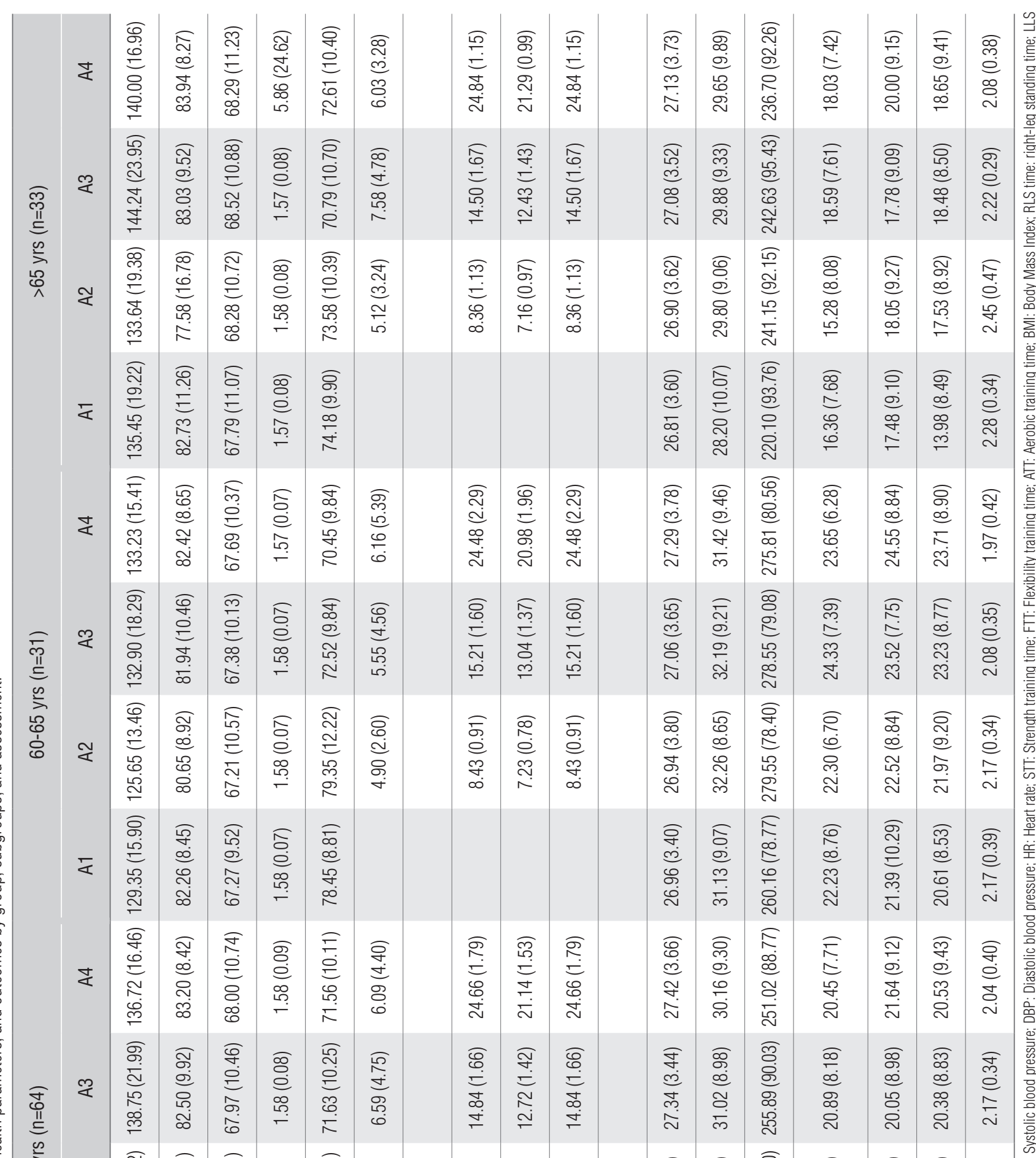

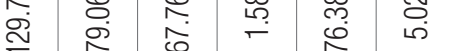


Table 2. Results of repeated-measures ANOVA by group and subgroups (post-hoc analysis: Bonferroni test).

\begin{tabular}{|c|c|c|c|c|c|}
\hline Group/Subgroup & Outcome & $\begin{array}{c}\text { A1-A2-A3-A4 } \\
\text { (p-value) }\end{array}$ & $\mathrm{A} 1-\mathrm{A} 2$ & A1-A3 & A1-A4 \\
\hline \multirow{7}{*}{$>60$ yrs $(n=64)$} & $\mathrm{BMI}\left(\mathrm{Kg} / \mathrm{m}^{2}\right)$ & $0.049^{*}$ & $-0.067(-0.409 ; 0.274)$ & $-0.230(-0.569 ; 0.108)$ & $-0.313(-0.688 ;-0.002)^{\star}$ \\
\hline & Strength (Kgf) & $0.009^{*}$ & $-0.484(-0.133 ; 0.164)$ & $-0.859(-0.365 ;-0.354)^{*}$ & $-0.000(-0.742 ; 0.742)$ \\
\hline & Flexibility (mm) & $<0.001^{\star}$ & $-0.7 .453(-0.0 .209 ;-0.697)^{\star}$ & $-0.8 .703(-0.1 .089 ;-0.317)^{\star}$ & $-0.3 .828(-0.4 .866 ;-0.790)^{\star}$ \\
\hline & $\mathrm{VO}_{2 \max }(\mathrm{ml} / \mathrm{Kg} / \mathrm{min})$ & $0.020^{*}$ & $0.617(-0.855 ; 3.089)$ & $-0.048(-0.093 ;-0.002)^{*}$ & $-0.603(-0.863 ; 0.657)$ \\
\hline & RLS test (sec) & $0.048^{*}$ & $-0.422(-0.946 ; 2.102)$ & $-0.672(-0.363 ; 2.019)$ & $-0.266(-0.580 ;-0.003)^{\star}$ \\
\hline & LLS test (sec) & $<0.001^{\star}$ & $-0.578(-0.711 ;-0.445)^{*}$ & $-0.734(-0.925 ;-0.544)^{*}$ & $-0.891(-0.333 ;-0.448)^{\star}$ \\
\hline & MGV (sec) & $<0.001^{\star}$ & $-0.115(-0.225 ;-0.005)^{*}$ & $0.057(-0.033 ; 0.146)$ & $0.182(0.075 ; 0.289)^{*}$ \\
\hline \multirow{7}{*}{$60-65$ yrs $(n=31)$} & $\mathrm{BMI}\left(\mathrm{Kg} / \mathrm{m}^{2}\right)$ & 0.211 & $0.024(-0.507 ; 0.554)$ & $-0.102(-0.719 ; 0.516)$ & $-0.329(-0.944 ; 0.286)$ \\
\hline & Strength (Kgf) & 0.245 & $-0.129(-0.759 ; 0.500)$ & $-0.065(-0.051 ; 0.922)$ & $-0.290(-0.073 ; 1.492)$ \\
\hline & Flexibility $(\mathrm{mm})$ & $0.002^{*}$ & $-0.9 .387(-0.6 .272 ;-0.502)^{*}$ & $-0.8 .387(-0.5 .687 ;-0.087)^{\star}$ & $-0.5 .645(-0.1 .990 ; 0.699)$ \\
\hline & $\mathrm{VO}_{2 \max }(\mathrm{ml} / \mathrm{Kg} / \mathrm{min})$ & 0.123 & $-0.068(-0.859 ; 2.722)$ & $-0.102(-0.404 ; 1.201)$ & $-0.416(-0.735 ; 1.904)$ \\
\hline & RLS test (sec) & 0.087 & $-0.129(-0.286 ; 2.028)$ & $-0.129(-0.680 ; 1.422)$ & $-0.161(-0.848 ; 0.525)$ \\
\hline & LLS test (sec) & $0.011^{*}$ & $-0.355(-0.927 ; 1.217)$ & $-0.613(-0.550 ; 0.324)$ & $-0.097(-0.018 ;-0.175)^{\star}$ \\
\hline & MGV (sec) & $0.001^{*}$ & $-0.002(-0.123 ; 0.120)$ & $0.082(-0.055 ; 0.219)$ & $0.192(0.010 ; 0.374)^{*}$ \\
\hline \multirow{7}{*}{$>65$ yrs $(n=33)$} & $\mathrm{BMI}\left(\mathrm{Kg} / \mathrm{m}^{2}\right)$ & 0.120 & $-0.093(-0.506 ; 0.320)$ & $-0.277(-0.599 ; 0.044)$ & $-0.329(-0.757 ; 0.100)$ \\
\hline & Strength (Kgf) & 0.107 & $-0.600(-0.060 ; 0.860)$ & $-0.675(-0.834 ; 0.484)$ & $-0.450(-0.989 ; 1.089)$ \\
\hline & Flexibility (mm) & $<0.001^{\star}$ & $-0.1 .050(-0.9 .027 ;-0.073)^{*}$ & $-0.2 .525(-0.9 .457 ;-0.593)^{\star}$ & $-0.6 .600(-0.1 .754 ;-0.446)^{*}$ \\
\hline & $\mathrm{VO}_{2 \max }(\mathrm{ml} / \mathrm{Kg} / \mathrm{min})$ & $0.007^{\star}$ & $1.083(-0.379 ; 4.545)$ & $-0.230(-0.546 ;-0.006)^{\star}$ & $-0.667(-0.504 ; 1.171)$ \\
\hline & RLS test (sec) & 0.143 & $-0.575(-0.151 ; 3.001)$ & $-0.300(-0.021 ; 3.421)$ & $-0.525(-0.547 ; 0.497)$ \\
\hline & LLS test (sec) & $<0.001^{\star}$ & $-0.550(-0.499 ;-0.601)^{*}$ & $-0.500(-0.446 ;-0.554)^{\star}$ & $-0.675(-0.097 ;-0.253)^{*}$ \\
\hline & MGV (sec) & $<0.001^{\star}$ & $-0.163(-0.322 ;-0.003)^{*}$ & $0.060(-0.065 ; 0.185)$ & $0.202(0.056 ; 0.348)^{\star}$ \\
\hline
\end{tabular}

Values of mean differences are expressed as difference (95\% Confidence Interval). BMI: Body Mass Index; RLS time: right-leg standing time; LLS time: left-leg standing time; MGV: maximum gait velocity. * indicates statistical significance $(\mathrm{p}<0.05)$

Table 3. Cohen index (d) for outcomes by group, subgroups and assessment.

\begin{tabular}{|c|c|c|c|c|}
\hline Group/Subgroup & Outcome & $\mathrm{A} 1-\mathrm{A} 2$ & A1-A3 & $\mathrm{A} 1-\mathrm{A} 4$ \\
\hline \multirow{7}{*}{$<60$ yrs $(\mathrm{n}=64)$} & $\mathrm{BMI}\left(\mathrm{Kg} / \mathrm{m}^{2}\right)$ & 0.02 & 0.07 & 0.09 \\
\hline & Strength (Kgf) & 0.17 & 0.20 & 0.11 \\
\hline & Flexibility (mm) & 0.20 & 0.21 & 0.15 \\
\hline & $\mathrm{VO}_{2 \max }(\mathrm{ml} / \mathrm{Kg} / \mathrm{min})$ & -0.07 & 0.24 & 0.19 \\
\hline & RLS test (sec) & 0.04 & 0.07 & 0.24 \\
\hline & LLS test (sec) & 0.28 & 0.41 & 0.42 \\
\hline & MGV (sec) & -0.28 & 0.16 & 0.48 \\
\hline \multirow{7}{*}{$60-65$ yrs $(n=31)$} & $\mathrm{BMI}\left(\mathrm{Kg} / \mathrm{m}^{2}\right)$ & -0.01 & 0.03 & 0.09 \\
\hline & Strength (Kgf) & 0.13 & 0.12 & 0.03 \\
\hline & Flexibility (mm) & 0.25 & 0.23 & 0.20 \\
\hline & $\mathrm{VO}_{2 \max }(\mathrm{ml} / \mathrm{Kg} / \mathrm{min})$ & 0.01 & 0.26 & 0.19 \\
\hline & RLS test (sec) & 0.12 & 0.24 & 0.33 \\
\hline & LLS test (sec) & 0.15 & 0.30 & 0.36 \\
\hline & MGV (sec) & 0.00 & 0.22 & 0.47 \\
\hline \multirow{7}{*}{$>65$ yrs $(n=33)$} & $\mathrm{BMI}\left(\mathrm{Kg} / \mathrm{m}^{2}\right)$ & 0.03 & 0.08 & 0.09 \\
\hline & Strength (Kgf) & 0.17 & 0.17 & 0.15 \\
\hline & Flexibility (mm) & 0.23 & 0.24 & 0.18 \\
\hline & $\mathrm{VO}_{2 \max }(\mathrm{ml} / \mathrm{Kg} / \mathrm{min})$ & -0.14 & 0.29 & 0.22 \\
\hline & RLS test (sec) & 0.06 & 0.03 & 0.28 \\
\hline & LLS test (sec) & 0.41 & 0.53 & 0.52 \\
\hline & MGV (sec) & -0.40 & 0.19 & 0.56 \\
\hline
\end{tabular}

The Cohen index was calculated as follows: $d_{\text {repeated measures }}=$ (mean1 - mean2)/(pooled standard deviation/standard error of the difference). BMI: Body Mass Index; RLS time: right-leg standing time; LLS time: left-leg standing time; MGV: maximum gait velocity. 
Table 4. Percentage of efficient women by group, subgroups, and assessment.

\begin{tabular}{lcccccccccc} 
& \multicolumn{3}{c}{$>60 \mathrm{yrs}(\mathrm{n}=64)$} & \multicolumn{3}{c}{$60-65 \mathrm{yrs}(\mathrm{n}=31)$} & \multicolumn{3}{c}{$>65 \mathrm{yrs}(\mathrm{n}=33)$} \\
& A2 & A3 & A4 & A2 & A3 & A4 & A2 & A3 & A4 \\
\hline \% efficient women & $59 \%$ & $47 \%$ & $56 \%$ & $68 \%$ & $61 \%$ & $81 \%$ & $65 \%$ & $45 \%$ & $52.5 \%$ \\
\hline$\%$ non-efficient women & $41 \%$ & $53 \%$ & $44 \%$ & $32 \%$ & $39 \%$ & $19 \%$ & $35 \%$ & $55 \%$ & $47.5 \%$ \\
\hline
\end{tabular}

Table 5. Cohen index ( $d$ ) for outcomes by group, subgroups and non-efficient/efficient subjects.

\begin{tabular}{|c|c|c|c|c|}
\hline \multirow{2}{*}{ Group } & \multicolumn{4}{|c|}{ Non-efficient vs. Efficient women } \\
\hline & Outcome & A2 & A3 & A4 \\
\hline \multirow{7}{*}{$<60$ yrs $(\mathrm{n}=64)$} & $\mathrm{BMI}\left(\mathrm{Kg} / \mathrm{m}^{2}\right)$ & 0.33 & 0.36 & 0.19 \\
\hline & Strength (Kgf) & 0.01 & 0.27 & 0.31 \\
\hline & Flexibility (mm) & 0.42 & 0.5 & 0.57 \\
\hline & $\mathrm{VO}_{2 \max }(\mathrm{ml} / \mathrm{Kg} / \mathrm{min})$ & 0.5 & 0.35 & 0.65 \\
\hline & RLS test (sec) & 1.27 & 1.39 & 1.26 \\
\hline & LLS test (sec) & 1.34 & 1.35 & 1.18 \\
\hline & MGV (sec) & 0.38 & 0.14 & 0.18 \\
\hline \multirow{7}{*}{$60-65$ yrs ( $n=31)$} & $\mathrm{BMI}\left(\mathrm{Kg} / \mathrm{m}^{2}\right)$ & 0.59 & 0.29 & 0.4 \\
\hline & Strength (Kgf) & 0.14 & 0.56 & 0.47 \\
\hline & Flexibility (mm) & 0.14 & 0.09 & 0.33 \\
\hline & $\mathrm{VO}_{2 \max }(\mathrm{ml} / \mathrm{Kg} / \mathrm{min})$ & 0.62 & 0.47 & 0.77 \\
\hline & RLS test (sec) & 1.27 & 0.74 & 1.33 \\
\hline & LLS test (sec) & 1.14 & 1.12 & 1.29 \\
\hline & MGV (sec) & 0.18 & $<0.01$ & 0.34 \\
\hline \multirow{7}{*}{$>65$ yrs $(\mathrm{n}=33)$} & BMI $\left(\mathrm{Kg} / \mathrm{m}^{2}\right)$ & 0.44 & 0.29 & 0.33 \\
\hline & Strength (Kgf) & 0.06 & 0.27 & 0.64 \\
\hline & Flexibility (mm) & 0.22 & 0.69 & 0.34 \\
\hline & $\mathrm{VO}_{2 \max }(\mathrm{ml} / \mathrm{Kg} / \mathrm{min})$ & 0.27 & 0.27 & 0.61 \\
\hline & RLS test (sec) & 0.82 & 1.39 & 0.85 \\
\hline & LLS test (sec) & 0.83 & 1.18 & 1.03 \\
\hline & MGV (sec) & 0.32 & 0.21 & 0.69 \\
\hline
\end{tabular}

The Cohen index was calculated as follows: $d_{\text {unnepeated measures }}=($ mean1 - mean2)/pooled standard deviation. BMI: Body Mass Index; RLS time: right-leg standing time; LLS time: left-leg standing time; MGV: maximum gait velocity.

an important differentiator in terms of activity planning and dose determination.

In a general analysis, as mentioned above, the program was effective in reversing and mitigating changes due to aging $^{10,49}$, contrary to what has been found by other authors in interventions aimed at reducing falls ${ }^{15}$. Nonetheless, one of the most interesting findings in this study comes from a different interpretation of the results according to the type of analysis in question, which may explain the controversies found in the literature ${ }^{14}$. Hence, inferential analysis identified important changes in the older subgroup, especially with respect to flexibility, balance, and aerobic consumption in the short and long term. These trends contrasted with the effect sizes, considered to be parameters of the highest clinical and practical applicability, in which as regards older individuals' balance the changes were categorized as low or non-existent in the short term and only moderate in the long term. For this reason, it is even more important to plan the analysis properly before interpreting the data, by establishing clear goals and managing clinical parameters ${ }^{13,50}$ and even calculation of the dose-response relationship ${ }^{51}$.

In this sense, the time of exposure to intervention has been identified as another possible determinant of efficiency taking into account that, in some studies, the amount of physical activity did not reach the minimum recommended dose ${ }^{40}$. From this perspective, it is possible to identify the benefits, in terms of efficiency, based on the amount of time spent on each type of exercise. In our study, the younger participants (60-65 yrs) showed higher efficiency, i.e. more individuals benefitted from the program, exerting less effort. The more elderly individuals needed more time on each type of exercise to be able to achieve beneficial changes.

In addition, the proportion of efficient individuals may decrease over time in more elderly subjects (aged $>65$ yrs) or when the sample is not separated by age subgroups, the percentage of efficient individuals only being increased in the older women. This scenario casts doubt not only on the intensity and effectiveness of 
physical activity, but also on the doses employed and the relative importance of the participants' adherence to the program.

Also, the benefits, when minimum in terms of static balance and aerobic consumption, may help to identify the women who will not profit from the physical activity program. These elderly people may need a different type of intervention/ treatment if they belong to the same target population. It is therefore necessary to accurately identify participants' adherence to the program as this can partly determine differences in behavior among subjects.

Finally, with regard to the factors that distinguish efficient individuals from non-efficient individuals in the group and subgroups, only age had statistical significance, which may be in agreement with the need to take into account age divisions, both inter- and intra-group, when evaluating the effects of physical activity on the elderly ${ }^{19}$, particularly individuals older than 65 years. The failure of measures such as weight or BMI in differentiating efficiency could support current evidence in favor of disregarding measures such as BMI as an indicator of risk of mortality in the elderly, with other factors, such as a sedentary lifestyle, being more important ${ }^{52}$.

These results, in agreement with those of other authors ${ }^{53}$, suggest the importance of investigating the target population's health needs, activity dose, and demographics before implementing programs, especially if differences between population features have been identified ${ }^{9,21,54}$. The establishment of specific groups of individuals may mitigate the discrepancy between ideal versions of programs and their practical implementation.

To our knowledge, this is the first study to investigate the efficiency of an exercise program intended for older people. However, several limitations were detected. A sample consisting solely of women, as well as the impact of different sample sizes of the group and subgroups on statistical significance, partly mitigated by the Cohen index, may restrict the extrapolation of our results. As mentioned, several interruptions occurred along the intervention, but their influence on the results was not determined because the participants' physical activity during this period was not assessed. Likewise, in spite of other studies having reported the permanence of changes achieved by the programs for long periods of time after their completion ${ }^{55,56}$, a follow-up investigation was not carried out after this program, which precludes any knowledge about how the changes found in participants' physical capacity evolved. Finally, the absence of a control group reduces the internal validity of the present study, although randomized controlled trials cannot be considered the only source of scientific evidence in complex interventions ${ }^{57}$ and other studies with similar designs have shown their ability to identify effects in the same target population ${ }^{49,58}$.

For these reasons, it seems necessary to conduct further research in order to carry out other efficiency measures with a view to determining the effects of these programs, studying the influence of other parameters, both physiological (body composition, oxidation) and clinical (falls, fall-related injuries), and determining dose-response relationship in specific populations.

\section{Conclusions : :}

Adapted physical activity is effective in changing the physical condition of older women. However, it is necessary to establish the activity dose and to standardize the analysis of results relative to the purpose of the study (e.g., determination of efficiency, clinical evaluation). In this sense, if physical activity is to be translated into health in older women, their age, both inter- and intra-groups, their adherence to the program, and the actual time they spend on each type of exercise should be taken into account. The DEA allows the assessment of the results of the time spent on physical activity in terms of health concerns.

\section{References : :}

1. IBGE. Breves notas sobre a mortalidade no Brasil no período 2000-2005. Rio de Janeiro: Instituto Brasileiro de Geografia Estatística; 2006.

2. Thelen DG, Wojcik LA, Schultz AB, Ashton-Miller JA, Alexander NB. Age differences in using a rapid step to regain balance during a forward fall. J Gerontol A Biol Sci Med Sci. 1997;52(1):M8-13.

3. Frontera WR, Hughes VA, Fielding RA, Fiatarone MA, Evans WJ, Roubenoff R. Aging of skeletal muscle: 12-yr longitudinal study. J Appl Physiol. 2000;88(4):1321-6.

4. Janssen I, Heymsfield SB, Wang ZM, Ross R. Skeletal muscle mass and distribution in 468 men and women aged 18-88 yr. J Appl Physiol. 2000;89(1):81-8.

5. de Jong N, Chin A Paw MJ, de Groot LCPG, de Graaf C, Kok FJ, van Staveren WA. Functional biochemical and nutrient indices in frail erderly people are partly affected by dietary supplements but not by exercise. J Nutr. 1999;129(11):2028-36.
6. Zhong S, Chen CN, Thompson LV. Sarcopenia of ageing: functional, structural and biochemical alterations. Rev Bras Fisioter. 2007;11(2):91-7.

7. Binder EF, Schechtman KB, Ehsani AA, Steger-May K, Brown M, Sinacore DR, et al. Effects of exercise training on frailty in community-dwelling older adults: results of a randomized controlled trial. J Am Geriatr Soc. 2002;50(12):1921-8.

8. Ueno M, Kawai S, Mino T, Kamoshita H. Systematic review of fall-related factors among the house-dwelling elderly in Japan. Nihon Ronen Igakkai Zasshi. 2006;43(1):92-101.

9. Krause MP, Januário RS, Hallage T, Haile L, Miculis CP, Gama MP, et al. A comparison of functional fitness of older Brazilian and American women. J Aging Phys Act 2009;17(4):387-97

10. Polidori MC, Mecocci P, Cherubini A, Senin U. Physical activity and oxidative stress during aging. Int J Sports Med. 2000;21(3):154-7. 
11. Hauer K, Becker C, Lindemann U, Beyer N. Effectiveness of physical training on motor performance and fall prevention in cognitively impaired older persons: a systemic review. Am J Phys Med Rehabil. 2006;85(10):847-57.

12. Sherrington C, Lord SR, Finch CF. Physical activity interventions to prevent falls among older people: update of the evidence. J Sci Med Sport. 2004;7(1 Suppl):43-51.

13. Gillespie LD, Robertson MC, Gillespie WJ, Lamb SE, Gates S, Cumming RG, et al. Interventions for preventing falls in older people living in the community. Cochrane Database Syst Rev. 2009(2):CD007146

14. Bleijlevens MH, Hendriks MR, van Haastregt JC, van Rossum E, Kempen GI, Diederiks JP, et al. Process factors explaining the ineffectiveness of a multidisciplinary fall prevention programme: a process evaluation. BMC Public Health. 2008;24(8):332.

15. Baker MK, Atlantis E, Fiatarone Singh MA. Multi-modal exercise programs for older adults. Age Ageing. 2007;36(4):375-81.

16. Tinetti ME. Multifactorial fall-prevention strategies: time to retreat or advance. J Am Geriatr Soc. 2008;56(8):1563-5

17. Lee DC, Sui X, Blair SN. Does physical activity ameliorate the health hazards of obesity? $\mathrm{Br} \mathrm{J}$ Sports Med. 2009;43(1):49-51.

18. Campbell AJ, Robertson MC. Not a retreat, but advancing on numerous fronts. J Am Geriatr Soc. 2009:57(3):565-7.

19. Conn VS, Minor MA, Burks KJ, Rantz MJ, Pomeroy SH. Integrative review of physical activity intervention research with aging adults. J Am Geriatr Soc. 2003;51(8):1159-68.

20. Laine J, Finne-Soveri UH, Björkgren M, Linna M, Noro A, Häkkinen U. The association between quality of care and technical efficiency in long-term care. Int J Qual Health Care. 2005;17(3): 259-67.

21. IBGE. Perfil dos idosos responsáveis pelos domicílios no Brasil-2000. Rio de Janeiro: Instituto Brasileiro de Geografia e Estatística; 2002.

22. WHO. Report of a WHO Expert Committee Technical Report Series, No 854. Physical status: the use and interpretation of anthropometry. Geneva: World Health Organization; 1995.

23. Greve P, Wanderley F, Rebelatto JR. The effects of periodic interruptions of physical activities on the physical capacities of adult active women. Arch Gerontol Geriatr. 2009;49(2):268-71.

24. Vaz M, Hunsberger S, Diffey B. Prediction equations for handgrip strength in healthy Indian male and female subjects encompassing a wide age range. Ann Hum Biol. 2002;29(2):131-41.

25. Massy-Westropp NM, Gill TK, Taylor AW, Bohannon RW, Hill CL. Hand Grip Strength: age and gender stratified normative data in a population-based study. BMC Res Notes. 2011; 14(4):127.

26. Fess EE. Grip strength. In: Casanova JS, editor. Clinical assessment recommendations. $2^{\text {nd }}$ ed. Chicago: American Society of Hand Therapists; 1992. p. 41-5.

27. Peolsson A, Hedlund R, Oberg B. Intra- and inter-tester reliability and reference values for hand strength. J Rehabil Med. 2001;33(1):36-41.

28. Chung PK, Yuen CK. Criterion-related validity of sit-and-reach tests in university men in Hong Kong. Percept Mot Skills. 1999;88(1):304-16.

29. Baltaci G, Un V, Tunay N, Besler A, Gerçeker S. Comparison of three different sit and reach tests for measurement of hamstring flexibility in female university students. $\mathrm{Br} \mathrm{J}$ Sports Med. 2003;37(1):59-61

30. Shaulis D, Golding LA, Tandy RD. Reliability of the AAHPERD functional fitness assessment across multiple practice sessions in older men and women. J Aging Phys Act. 1994;2(3):273-9.

31. Hurvitz EA, Richardson JK, Werner RA, Ruhl AM, Dixon MR. Unipedal stance testing as an indicator of fall risk among older outpatients. Arch Phys Med Rehabil. 2000;81(5):587-91.

32. Lin MR, Hwang HF, Hu MH, Wu HD, Wang YW, Huang FC. Psychometric comparisons of the timed up and go, one-leg stand, functional reach, and Tinetti balance measures in communitydwelling older people. J Am Geriatr Soc. 2004;52(8):1343-8.

33. Aveiro MC, Granito RN, Navega MT, Driusso P, Oishi J. Influence of a physical training program muscle strength, balance and gait velocity among women with osteoporosis. Rev Bras Fisioter. 2006;10(4):441-8

34. Matsudo SM, Matsudo VKR, Barros Neto TL, Araújo TL. Evolução do perfil neuromotor e capacidade funcional de mulheres fisicamente ativas de acordo com a idade cronológica. Rev Bras Med Esporte. 2003;9(6):365-76
35. Oberg T, Karsznia A, Oberg K. Basic gait parameters: reference data for normal subjects, 10-79 years of age. J Rehabil Res Dev. 1993;30(2):210-23.

36. Kline GM, Porcari JP, Hintermeister R, Freedson PS, Ward A, McCarron RF, et al. Estimation of V02max from a one-mile track walk, gender, age, and body weight. Med Sci Sports Exerc. 1987;19(3):253-9.

37. Fenstermaker KL, Plowman SA, Looney MA. Validation of the Rockport Fitness Walking Test in females 65 years and older. Res Q Exerc Sport. 1992;63(3):322-7.

38. O'Hanley S, Ward A, Zwiren L, McCarron R, Ross J, Rippe J. Validation of a one-mile walk test in 70-79 year olds. Med Sci Sports Exerc. 1987;19(Suppl 2):28.

39. Pickering TG, Hall JE, Appel LJ, Falkner BE, Graves J, Hill MN, et al. Recommendations for blood pressure measurement in humans and experimental animals: part 1: blood pressure measurement in humans: a statement for professionals from the Subcommittee of Professional and Public Education of the American Heart Association Council on High Blood Pressure Research. Circulation. 2005;111(5):697-716.

40. Kruger J, Buchner DM, Prohaska TR. The prescribed amount of physical activity in randomized clinical trials in older adults. Gerontologist. 2009;49(Suppl 1):S100-7.

41. Rebelatto JR, Morelli JG. Fisioterapia Geriátrica. 2nd ed. São Paulo: Manole; 2007.

42. Kawanabe K, Kawashima A, Sashimoto I, Takeda T, Sato Y, Iwamoto J. Effect of whole-body vibration exercise and muscle strengthening, balance, and walking exercises on walking ability in the elderly. Keio J Med. 2007;56(1):28-33.

43. Cohen J. Statistical Power Analysis for the Behavioral Sciences. $2^{\text {nd }}$ ed. Hillsdale, NJ: Lawrence Erlbaum Associates; 1988

44. Banker RD, Conrad RF, Strauss RP. A comparative application of data envelopment analysis and translog methods: an illustrative study of hospital production. Management Science. 1986;32(2):30-44

45. Charnes A, Cooper WW, Rhodes E. Measuring the efficiency of decision making units. Eur J Oper Res. 1978;2(6):429-44.

46. Sherman HD. Hospital efficiency measurement and evaluation. Empirical test of a new technique Med Care. 1984;22(10):922-38.

47. Cooper WW, Sieford L, Tone K. Data envelopment analysis. A comprehensive text with models, applications, reference and DEA-Solver software. Boston: Kluwer Academic Publishers; 2000.

48. Banker RD, Charnes A, Cooper WW. Some models for estimating technical and scale inefficiencies in data envelopment analysis. Management Science. 1984;30(9):1078-92.

49. Rebelatto JR, Castro AP. Effect of the adult revitalization program on the occurrence of falls among its participants. Rev Bras Fisioter. 2007;11(5):383-90.

50. Lord SR, Castell S, Corcoran J, Dayhew J, Matters B, Shan A, et al. The effect of group exercise on physical functioning and falls in frail older people living in retirement villages: a randomized, controlled trial. J Am Geriatr Soc. 2003:51(12):1685-92.

51. Radak Z, Chung HY, Koltai E, Taylor AW, Goto S. Exercise, oxidative stress and hormesis. Ageing Res Rev. 2008;7(1):34-42.

52. Flicker L, McCaul KA, Hankey GJ, Jamrozik K, Brown WJ, Byles JE, et al. Body mass index and survival in men and women aged 70 to 75. J Am Geriatr Soc. 2010;58(2):234-41.

53. Hendriks MR, Bleijlevens MH, van Haastregt JC, Crebolder HF, Diederiks JP, Evers SM, et al Lack of effectiveness of a multidisciplinary fall-prevention program in elderly people at risk: a randomized, controlled trial. J Am Geriatr Soc. 2008;56(8):1390-7.

54. Vogel T, Brechat PH, Leprêtre PM, Kaltenbach G, Berthel M, Lonsdorfer J. Health benefits of physical activity in older patients: a review. Int J Clin Pract. 2009;63(2):303-20.

55. Ivey FM, Tracy BI, Lemmer JT, NessAiver M, Metter EJ, Fozard JL, et al. Effects of strength training and detraining on muscle quality: age and gender comparisons. J Gerontol A Biol Sc Med Sci. 2000;55(3):B152-9.

56. Lemmer JT, Hurlbut DE, Martel GF, Tracy BL, Ivey FM, Metter EJ, et al. Age and gender responses to strength training and detraining. Med Sci Sports Exerc. 2000;32(8):1505-12.

57. Milanese S. The use of RCT's in manual therapy - are we trying to fit a round peg into a square hole? Man Ther. 2011;16(4):403-5

58. Rebelatto JR, Calvo JI, Orejuela JR, Portillo JC. Influence of a long-term physical activity program on hand muscle strength and body flexibility among elderly women. Rev Bras Fisioter 2006;10(1):127-32. 